\title{
Detailed monitoring as an essential tool for achieving energy performance targets in operation conditions: the HIKARI case study
}

\author{
Dimitri Guyot ${ }^{1,2}$, Florine Giraud ${ }^{1}$, Florian Simon ${ }^{2}$, David Corgier $^{2}$, Christophe Marvillet ${ }^{1}$, and Brice Tremeac $^{1}$ \\ ${ }^{1}$ Laboratoire du froid, des systèmes énergétiques et thermiques (Lafset), CNAM, 292 rue Saint Martin - 75003 Paris, France \\ ${ }^{2}$ MANASLU Ing., Savoie Technolac, BP80209 - 73374 Le Bourget du Lac, France
}

\begin{abstract}
The case study is the HIKARI project, the first net zero energy city block in Europe, gathering offices, housing and shops. The three mixed-use buildings composing the $12000 \mathrm{~m}^{2}$ block pool their energy through shared innovative energy production systems coupled with large capacity energy storage units. HIKARI is fully monitored with more than 10000 measurement points collected for several years of operating conditions. Through the identification and analysis of an energy consumption drift caused by the malfunctioning of a particular system, we demonstrate the importance of adopting a global approach when conceiving a building, especially if low energy targets are to be reached. The analysis of the monitoring results also highlights the value of detailed monitoring for identifying malfunctions, for assessing the relevance of the technical choices made during the design phase, and as an essential tool for achieving the objective of energy performance under operating conditions.
\end{abstract}

\section{Building description}

\subsection{Overview}

HIKARI is a $12310 \mathrm{~m}^{2}$ city block located in Lyon, France (454'31.1"N 449'09.5"E, altitude $240 \mathrm{~m}$ ) and operating since July 2015 . The project has been designed to be the first net zero energy city block in Europe [1] and is composed of three mixed-use buildings: Nishi, Minami and Higashi (from left to right on Fig. 1). HIKARI is entirely monitored with more than 10000 measurements points and is controlled through the BEMS interface (Building Energy Management System).

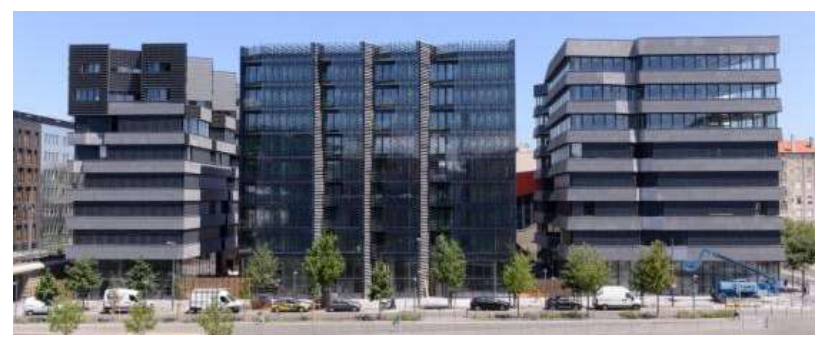

Fig. 1. South façade of HIKARI

\subsection{Building's use}

The ground floors of each buildings are occupied by different shops. Higashi is composed of seven floors subdivided in offices according to the user's needs while Minami is separated in 32 apartments. The first five floors of Nishi are occupied by offices and the two last floors are composed of four duplex apartments. The different usages and floor areas of the buildings are gathered in Table 1.

Table 1. Floor areas summary

\begin{tabular}{|c|c|c|c|c|}
\hline Areas $\left(\mathrm{m}^{2}\right)$ & Offices & Housing & Shops & TOTAL \\
\hline Higashi & 5434 & - & 567 & $\mathbf{6 0 0 1}$ \\
\hline Minami & - & 2959 & 289 & $\mathbf{3 2 4 8}$ \\
\hline Nishi & 2338 & 570 & 153 & $\mathbf{3 0 6 1}$ \\
\hline TOTAL & $\mathbf{7 7 7 2}$ & $\mathbf{3 5 2 9}$ & $\mathbf{1 0 0 9}$ & $\mathbf{1 2 3 1 0}$ \\
\hline
\end{tabular}

\subsection{Envelope characteristics}

In order to achieve the net zero energy target, a particular attention has been given on the envelope quality. Its main characteristics are gathered in Table 2. Several measures have been taken such as exterior wall insulation, double glazing low emissivity for offices zones, triple glazing low emissivity for dwellings, thermal bridges treatment and air tightness (air leakage rate under $50 \mathrm{~Pa}$ of 0.6 $\mathrm{vol} / \mathrm{h})$.

Table 2. Envelope main characteristics

\begin{tabular}{|l|c|c|c|}
\hline \multicolumn{1}{|c|}{ Parameter } & Offices & Housing & Shops \\
\hline Wall's U value $\left[\mathrm{W} /\left(\mathrm{m}^{2} \cdot \mathrm{K}\right)\right]$ & 0.16 & 0.16 & 0.26 \\
\hline Ground floor $\mathrm{U}$ value $\left[\mathrm{W} /\left(\mathrm{m}^{2} \cdot \mathrm{K}\right)\right]$ & 0.18 & 0.18 & 0.18 \\
\hline Roof U value $\left[\mathrm{W} /\left(\mathrm{m}^{2} \cdot \mathrm{K}\right)\right]$ & 0.15 & 0.15 & - \\
\hline Windows U value $\left[\mathrm{W} /\left(\mathrm{m}^{2} \cdot \mathrm{K}\right)\right]$ & 1.40 & 0.75 & 1.40 \\
\hline Solar heat gain coefficient & 0.58 & 0.55 & 0.45 \\
\hline Visible light transmission & 0.78 & 0.65 & 0.75 \\
\hline
\end{tabular}

\footnotetext{
${ }^{*}$ Corresponding author: brice.tremeac@1ecnam.net
} 


\subsection{Energy production and distribution systems}

Heating and cooling systems are traditionally designed based on the annual peak needs. Such design method leads to oversized systems mostly operating at partial load. This results in stressful operating conditions and short-cycling, leading to low efficiency and increased operating and maintenance costs. Consequently, an approach using under-sized production systems coupled with heat storage and backup systems has been adopted. This allows to decorrelate the production and the distribution, allowing to undersize the main production unit and operate it under nominal conditions. This also guarantee a high efficiency and an increased system lifetime [2]. When properly controlled, those systems also provide a potential for peak load shifting [3]. The different innovative systems providing the energy needs are represented in Fig. 2. The heating needs are provided by a rapeseed oil cogeneration unit ( $98 \mathrm{~kW}$ of thermal power) as the main boiler and a condensing gas boiler $(300 \mathrm{~kW})$ as a backup. Both boilers are coupled to 7 hot water storage tanks of $4 \mathrm{~m}^{3}$ each organized in series. This corresponds to an available energy of $1.3 \mathrm{MWh}$ considering a use at $40^{\circ} \mathrm{C}$ of $\Delta \mathrm{T}$. The cooling needs are provided by an absorption chiller of 46 $\mathrm{kW}$ and a magnetic levitation chiller of $300 \mathrm{~kW}$ as a backup, coupled to a chilled water storage tank using phase change materials $\left(50 \mathrm{~m}^{3}, 0.61 \mathrm{MWh}\right)$. The electricity produced by the cogeneration unit $(75 \mathrm{~kW}$ of electric power) and photovoltaic panels $(188 \mathrm{kWp})$ can be consumed on site, injected on the grid, or stored in a battery pack $(100 \mathrm{kWh})$.

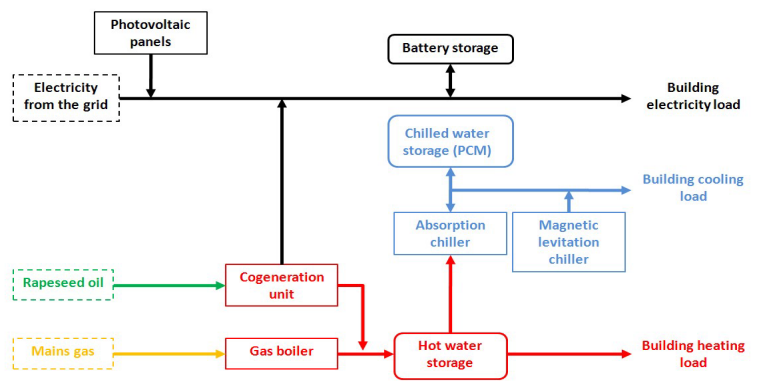

Fig. 2. Energy production and distribution systems

\section{Monitoring data analysis}

\subsection{Dysfunction identification}

After one year of monitoring, several dysfunctions have been identified, especially regarding the two shops of Higashi, i.e. a north-facing bank of $236 \mathrm{~m}^{2}$ and a southfacing restaurant of $320 \mathrm{~m}^{2}$. Indeed, unlike the rest of the project, the choice of the terminal heat emitters of the shops and their control strategy design have been left to the tenants. This means that they were not necessarily designed according to a global approach by considering the other equipment of the building, nor in accordance with the net zero energy target of the project. An annual heating and cooling needs analysis allowed us to identify an unusual high energy consumption for premises with an efficient envelope, represented in Fig. 3.

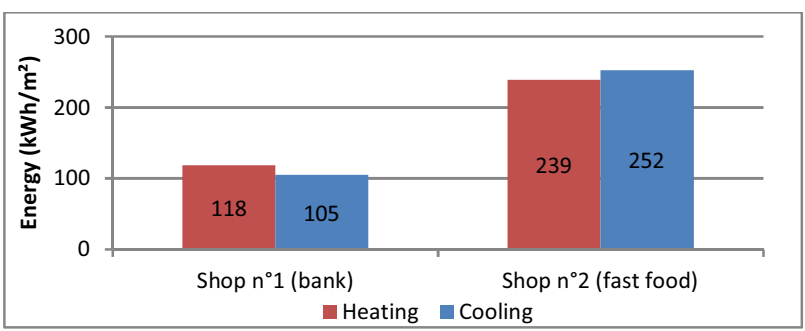

Fig. 3. Yearly heating and cooling needs for Higashi shops

A monthly analysis showed heating needs during summer and cooling needs during winter in a nonnegligible amount for both shops, as shown in Fig. 4 and Fig. 5. Note that due to a dysfunction of the monitoring devices, the month of November should not be considered in the analysis.

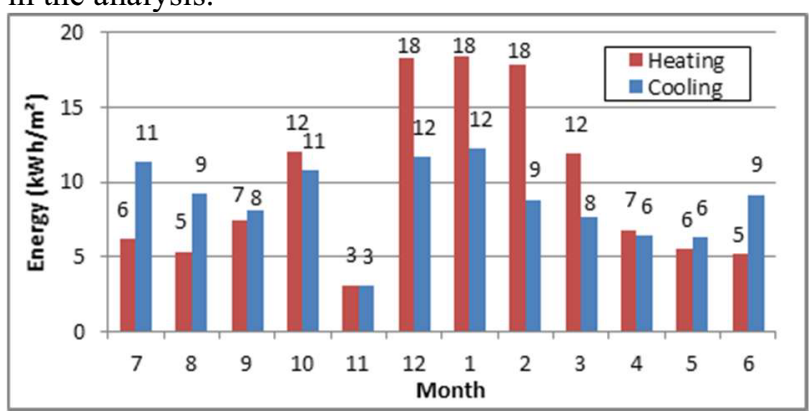

Fig. 4. Monthly heating and cooling needs for the bank

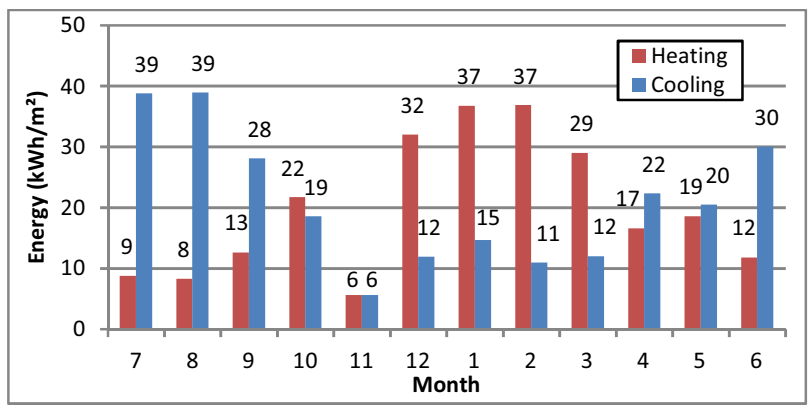

Fig. 5. Monthly heating and cooling needs for the restaurant

A dynamical analysis have been performed on the heating and cooling powers during one winter week and one summer week, chose for their representativeness. Simultaneous heating and cooling powers have been identified for both shops during winter, as shown in Fig. 6. Two distinct patterns can be observed for the bank, depending on the occupancy. High consumption of heating and cooling are observed during vacancy periods, i.e. at night and on closed days (Monday and Sunday), while the lowest consumptions occur during occupied periods. For an unknown reason, the cooling power shifts around $6 \mathrm{~kW}$ during vacancy periods, forcing the heating power to increase. As soon as cooling stops, the heating power decrease to a more reasonable power, around $2 \mathrm{~kW}$, which would most likely be the power observed in normal operation conditions. Regarding the restaurant, daily patterns of heating and cooling power can be observed, with night setbacks on Tuesday, Thursday, Friday, Saturday and Sunday. Inexplicably, there are no night setback on Monday and Wednesday. A morning heating power peak followed by a decrease around noon is observed almost every day of the week, however a cooling 
power of $8 \mathrm{~kW}$ is observed during occupancy periods. This cooling power cannot be used for any refrigeration device, since water is supplied at $13{ }^{\circ} \mathrm{C}$, meaning that it can only be used for space cooling only. The exact same observations can be drawn for both shops during summer, as shown in Fig. 7. Those poor control strategies results in extremely high energy consumptions, since the two shops account for $24 \%$ and $35 \%$ for heating and cooling energy needs respectively while they represent only $4.5 \%$ of the total surface. Those dysfunctions penalize the whole building in achieving its net zero energy target. In addition to these overconsumptions, the heat production systems are exposed to high return temperatures as shown in Fig. 8, while the exact opposite is needed to keep the storage stratified and allow the boiler to condense the water contained in the combustion gases. Indeed, the dew point temperature for natural gas composed at $95 \%$ of $\mathrm{CH}_{4}$ and combustion gases composed at $10 \%$ of $\mathrm{CO}_{2}$, which corresponds to typical operation conditions, is around $55^{\circ} \mathrm{C}$. The theoretical efficiency of the boiler is given for a water return temperature of $30{ }^{\circ} \mathrm{C}$, which is hardly reachable under real operating conditions. Consequently, a maximum return temperature of $40{ }^{\circ} \mathrm{C}$ has been chosen during the design phase, resulting in a $15{ }^{\circ} \mathrm{C}$ temperature difference compare to the combustion gases dew point temperature, which is sufficient to condense most of the water. However, the shops return temperature is under $40{ }^{\circ} \mathrm{C}$ during $2.5 \%$ of the operating time only. In addition, during $74 \%$ of the operating time the temperature is above the dew point temperature, at $55^{\circ} \mathrm{C}$. It is difficult to identify the exact cause of such dysfunction without on-site measurements and further information, but poorly designed equipment and/or poor control strategies could be involved. Similar issues have been identified on the others shops of the project, also inducing high return temperature, but their analysis is beyond the scope of this article.

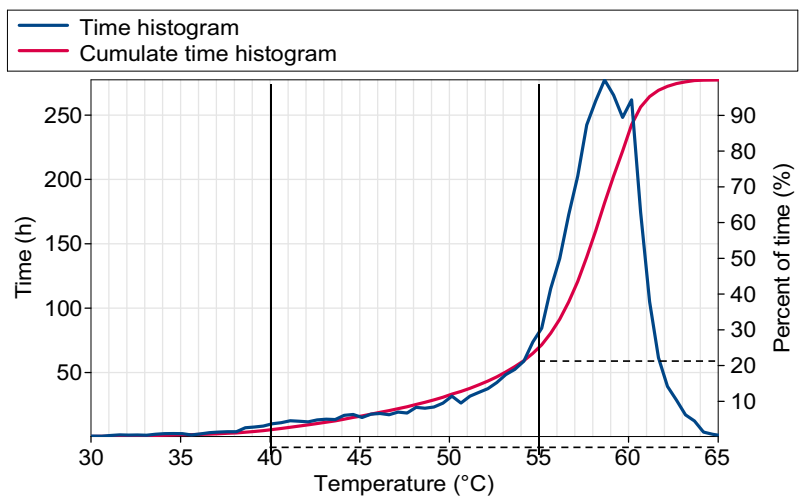

Fig. 8. Time repartition of the shops' return temperature from October to March

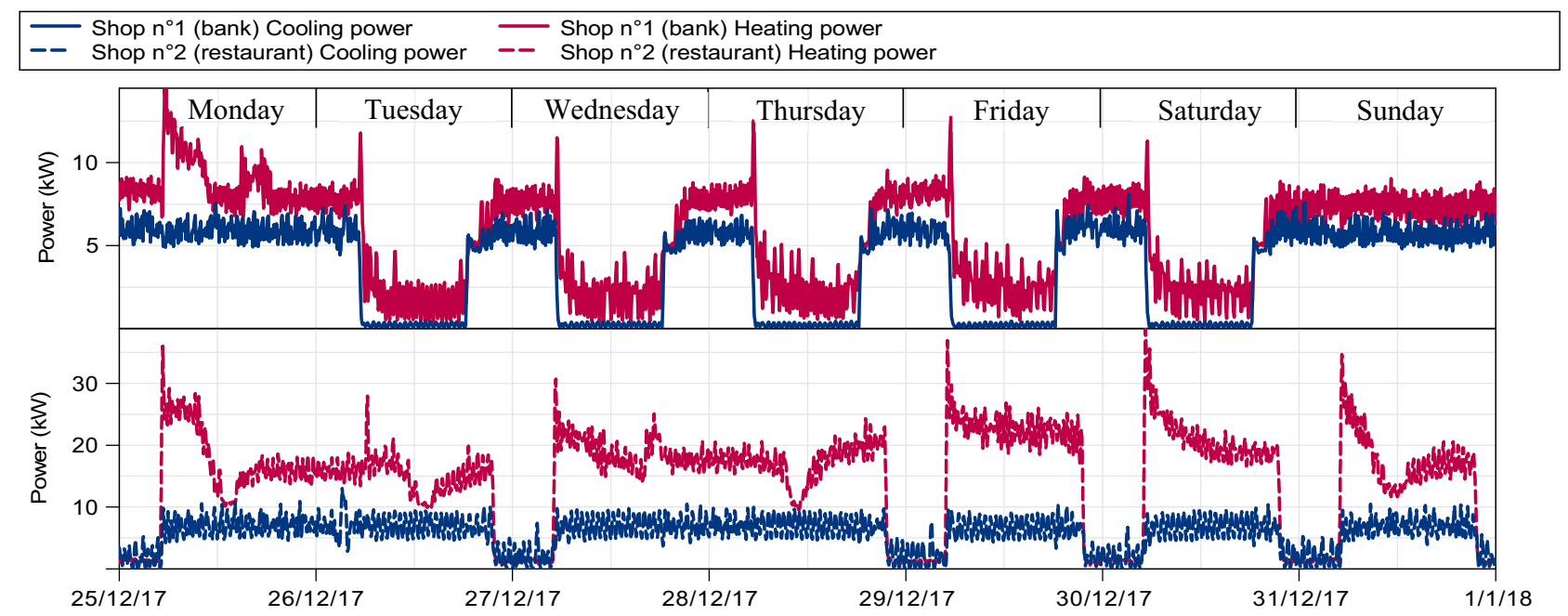

Fig. 6. Heating and cooling powers during one winter week

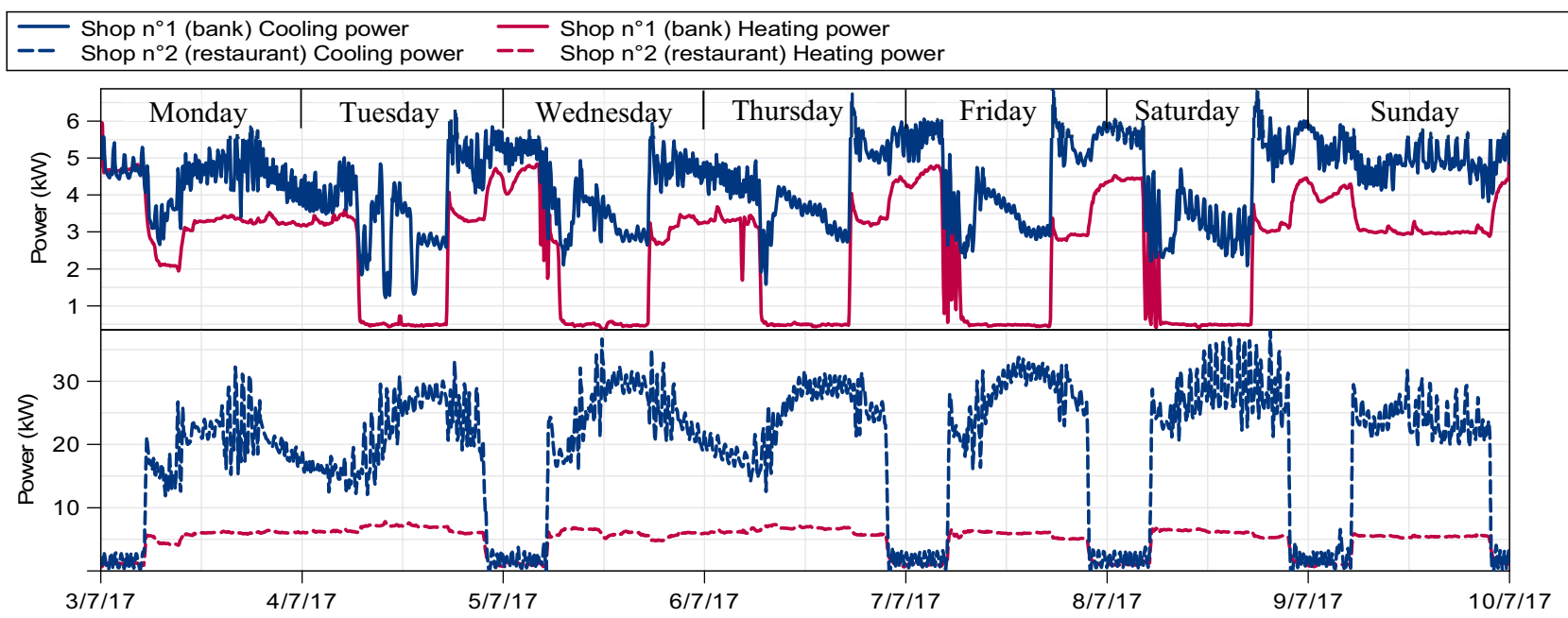

Fig. 7. Heating and cooling powers during one summer week 


\subsection{Effects on heat and cold production systems}

\subsubsection{Heat storage}

The seven water storage tanks are placed in series, meaning that the bottom of each tank is connected to the top of the next one. This allows stratification, which is essential in order to use the stored heat at the desired temperature without having to wait for the tanks to be fully charged [4]. Fig. 9 shows the typical functioning of the storage system during a weekday. However, during this period the gas boiler had to take over from the cogeneration unit due to functioning issues. Heating starts at 6 am in the whole building leading to high power needs up to $500 \mathrm{~kW}$ that the gas boiler cannot directly supply. Consequently, the tanks will successively discharge, starting from tank $n^{\circ} 7$ to tank $n^{\circ} 3$. Tanks 1 and 2 are still fully charged after the 6 hours discharge phase. As soon as the heating needs become lower than the produced heat, the tanks charge again, starting from tank $n^{\circ} 3$. The heat storage utility is clearly demonstrated, since the gas boiler can operate at its nominal power during $6 \mathrm{~h}$ while the heating needs fluctuate. The cogeneration unit and gas boiler control is based on the heat storage temperatures. Consequently, a functioning in accordance with the design assumptions in terms of storage temperatures is mandatory. Due to the unusually high return temperature of the shops mixing with the return temperature of the other circuits, the overall return temperature entering the

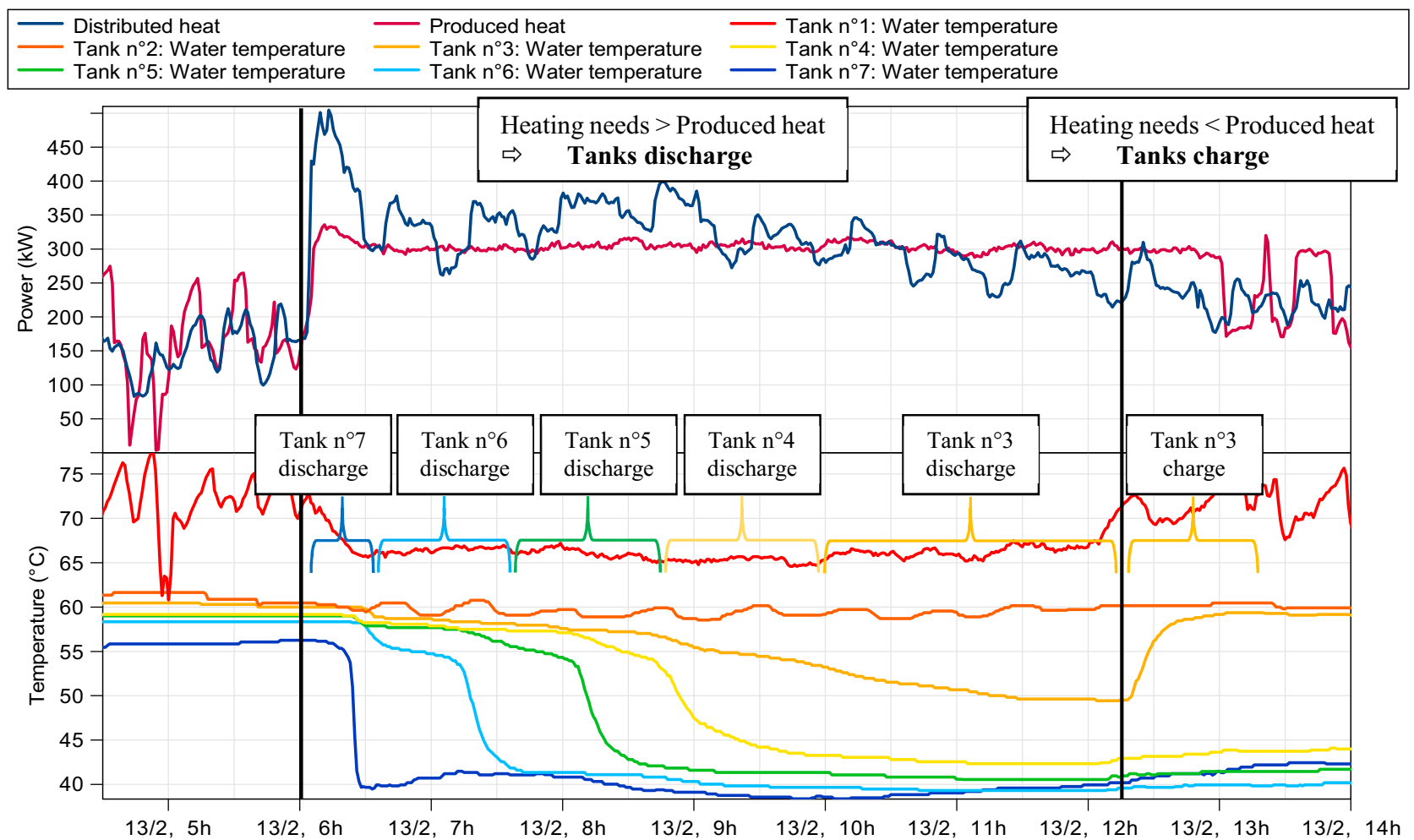

Fig. 9. Dynamical analysis of a discharge phase

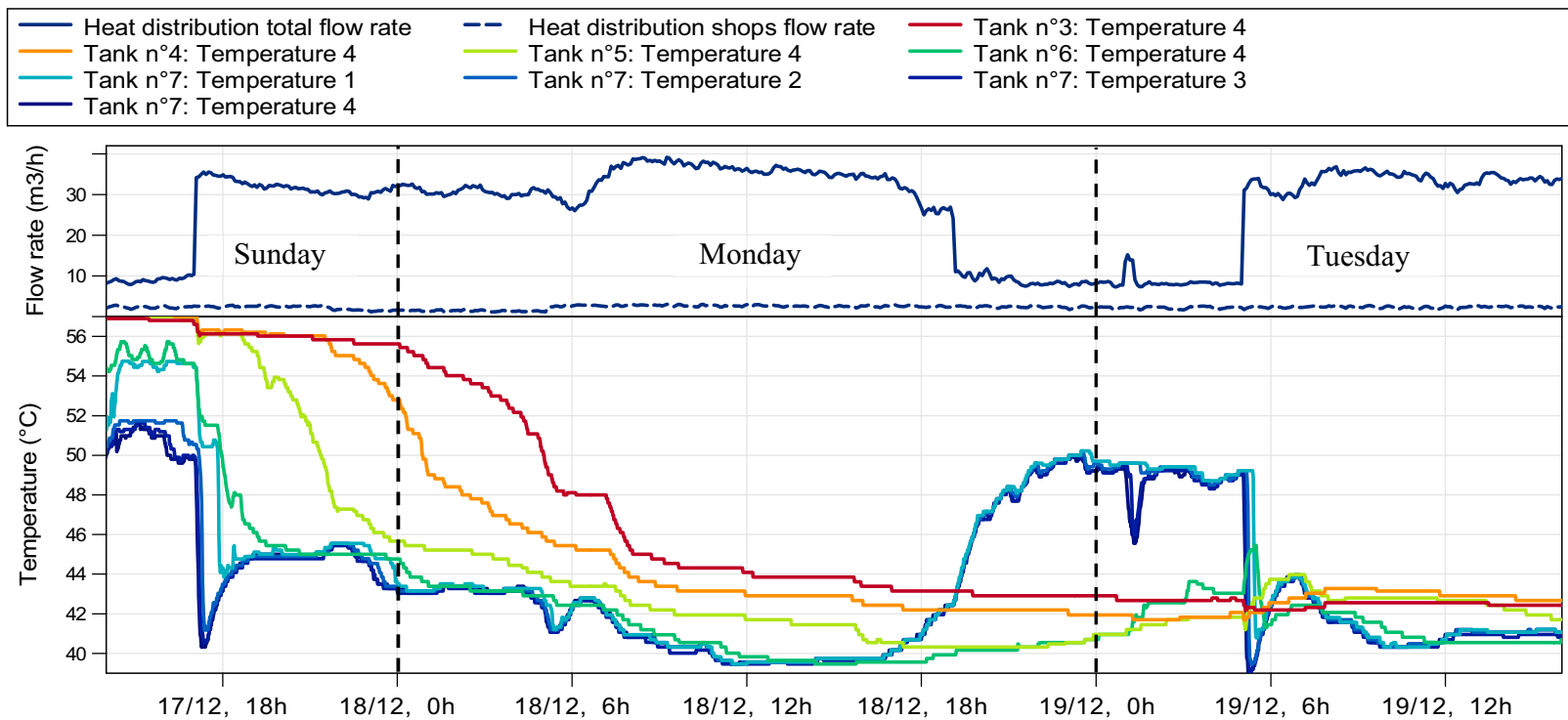

Fig. 10. Dynamical analysis of the heat storage destratification phenomenon 

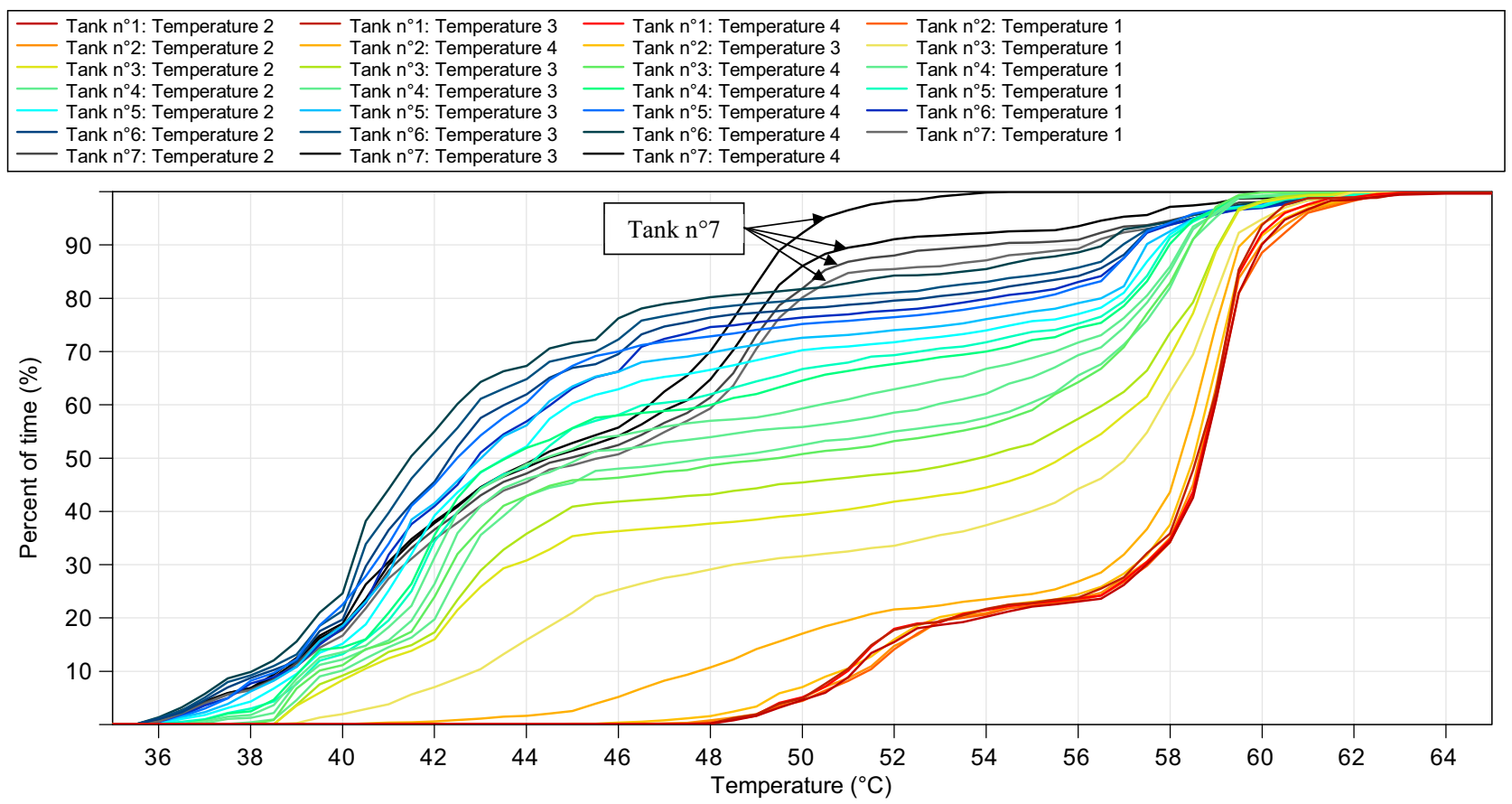

Fig. 11. Heat storage temperatures, cumulative time count over a correct stratification period

bottom of tank $n^{\circ} 7$ can be much higher than the $40^{\circ} \mathrm{C}$ initially planned. This causes the heat storage to destratify and can disrupt the control of the boilers. This situation is illustrated in Fig. 10, where a correct discharge phase over a period of high energy needs from Sunday $6 \mathrm{pm}$ to Monday $6 \mathrm{pm}$ (heating starts earlier at the beginning of the week) can be identified. During this period, the shops flow rate didn't weight enough in the overall mix compare to the total flow rate from the other zones of the building to substantially elevate the overall return temperature. However, as previously showed, heating doesn't stop on Monday's nights in the shops. Consequently as soon as heating stops in most of the zones, causing the total flow rate to decrease, the weight of the shops flow rate in the overall mix increase from $1 / 15$ to $1 / 3$ of the total flow rate. As a result, the overall return temperature drastically increase and heat up the last tank from the bottom to the top, leading to a temperature inversion. A temporal analysis of the tanks temperature has been performed over a 19 days period of high energy needs during which the stratification has been satisfying. The results are shown in Fig. 11 where the four temperatures of tank $n^{\circ} 7$ are decorrelated from the global behavior of the storage system, proving that the previously described situation is not an isolated phenomenon.

\subsubsection{Gas boiler}

While every system in the rest of the building is successfully controlled to keep a return temperature below $40{ }^{\circ} \mathrm{C}$ as shown in Fig. 12, the shops return temperatures are extremely high in view of the operating conditions needed for a satisfying functioning of the boiler. As a result, the return temperature of the gas boiler stays below $40{ }^{\circ} \mathrm{C}$ during $10 \%$ of its operating time as shown in Fig. 13. Moreover, it operate outside its design range during $90 \%$ of the time, strongly affecting its capacity to condense, leading to poor efficiency.

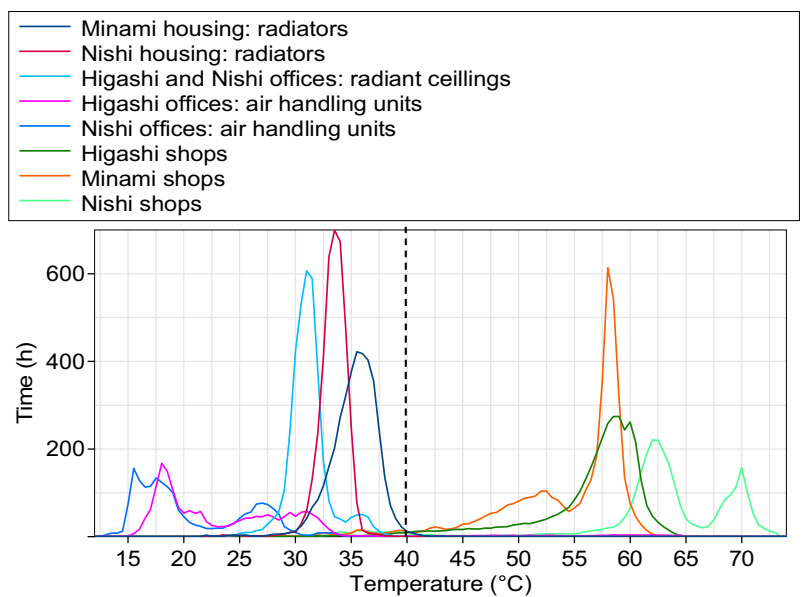

Fig. 12. Time repartition of the return temperatures of each heating circuit

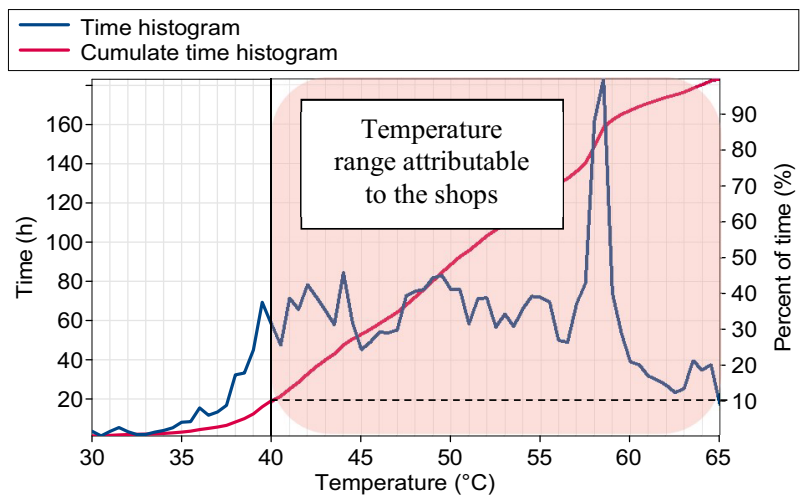

Fig. 13. Time repartition of the boiler return temperature from October to March

Consequently, the measured boiler efficiency is highly below its theoretical value as shown in Fig. 14, with a mean annual value of $79 \%$, compared to a theoretical efficiency of $97.4 \%$. 


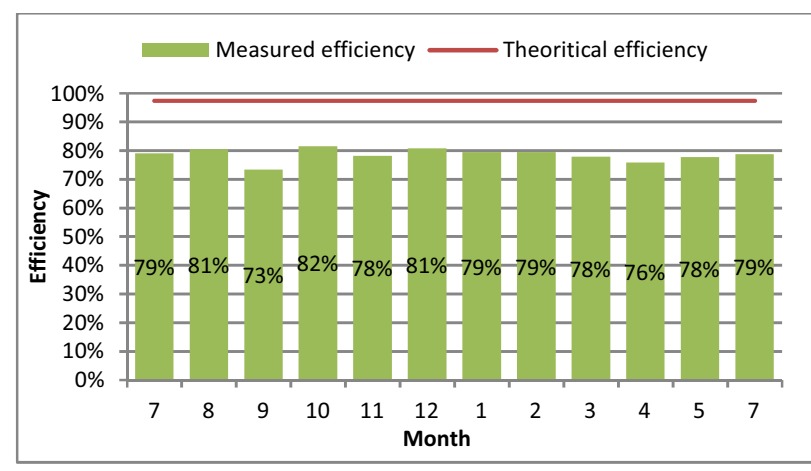

Fig. 14. Monthly efficiency of the gas boiler

\subsubsection{Chilled water storage}

Similarly to the heat production systems, the strategy adopted during the design phase was to use the chilled water storage to store energy at night using the absorption chiller, and discharge the storage during the day. This implies to have daily consumption patterns consisting in high needs during the day, and very low needs during the night. As shown in Fig. 15, the cooling production (in red) is constant at night around $46 \mathrm{~kW}$, meaning that the absorption chiller is running alone, without the magnetic chiller as a backup. However, as previously shown, the shops are consuming cooling energy at night (in blue), forcing the absorption chiller to directly supply the shops and limiting the storable energy. Unlike the planned functioning, energy in released at night to supply the shop's demand, and the chilled water storage is refilled during daytime, when the magnetic chiller starts. This led to a poor usage of the chilled water storage since $10 \%$ only of the supplied cooling energy went through the storage.

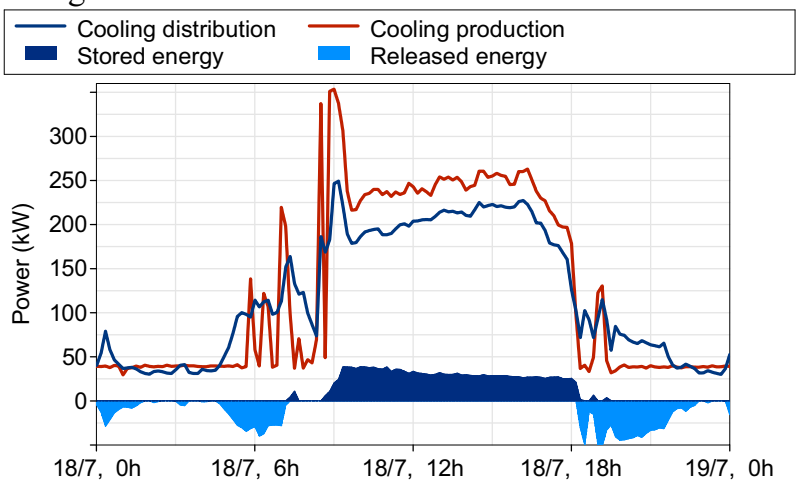

Fig. 15. Typical cooling power profile on a summer day

\section{Conclusion}

Starting from an annual energy consumption assessment which allowed to identify unusually high energy consumption for the two shops of Higashi building, we went through sharper dynamical analysis to identify the causes and consequences of what appear to be wrong design choices and poor control strategies. However, onsite audits and detailed equipment information are mandatory to draw any further conclusions. In addition to make the net zero energy target difficult to achieve, three of the multiples consequences of non-predicted high energy consumption and high return temperatures on a boiler-storage assembly and a chilled water storage (i.e. tank destratification, boiler's efficiency degradation and poor chilled water storage usage) have been identified and discussed thanks to detailed monitored data.

The detection of these malfunctions was made possible thanks to an annual operating report. Such steady monitoring allows for the identification of energy consumption drifts and appears to be essential to guarantee the building's energy performance over time, demonstrating the interest of detailed and complete monitoring. Such detail in building instrumentation allows to conduct low timestep dynamical analysis for a complete understanding of the systems' functioning. Consequently, any dysfunction can be detected, identified and understood, allowing for corrective action to be taken rapidly in order to reach the energy performance target set during the design phase under operating conditions.

The dynamical analysis of the boiler-storage assembly under operating conditions showed its interest, demonstrating another advantage of detailed monitoring, which is the evaluation of the relevance of the technical choices made during the design phase. The design of the shops terminal heat emitters and their control strategies shouldn't have been left to the tenants. They account for $24 \%$ and $35 \%$ of the heating and cooling energy needs respectively while they represent only $4.5 \%$ of the total surface. Such an experience illustrates the importance of adopting a global approach when conceiving a building, especially if low energy target are to be reached. Indeed, this often implies centralized and complex energy production systems operating under carefully designed rules that are very sensitive to the building's smallest dysfunction.

\section{References}

[1] Simon F, Piriou C, Corgier D, Nishimura N, Asakura $\mathrm{H}$, Ushiba $\mathrm{G}$, et al. Innovative design and commissioning of a positive energy balance plot in Lyon (France): The HIKARI project. Refrig. Sci. Technol., 2015, p. 4000-7. doi:10.18462/iir.icr.2015.0489.

[2] Simon F, Piriou C, Corgier D, Temeac B. Measured and simulated behavior of heat pump in low energy building: Short cycling and storage impact. Refrig. Sci. Technol., 2015, p. 4850-7. doi:10.18462/iir.icr.2015.0040.

[3] Berthou T. Développement de modèles de bâtiment pour la prévision de charge de climatisation et l'élaboration de stratégies d'optimisation énergétique et d'effacement. 2014.

[4] Han YM, Wang RZ, Dai YJ. Thermal stratification within the water tank. Renew Sustain Energy Rev 2009;13:1014-26. doi:10.1016/j.rser.2008.03.001. 